\title{
Evolutionary biology and the risk of scrapie disease in sheep
}

\author{
David Bruce Adams*
}

\author{
24 Noala Street, Aranda, ACT 2614, Australia
}

\begin{abstract}
Scrapie in sheep occurs in two forms. Classical scrapie, along with chronic wasting disease in deer, differs from all other prion diseases in being contagious and occurring as propagating epidemics. By contrast, atypical scrapie occurs sporadically and like most other prion diseases, such as Creutzfeldt-Jakob disease in humans, is regarded as noncontagious under natural conditions. This difference motivates the present study, which uses the perspective of evolutionary biology to explore whether atypical or non-contagious scrapie can transform to classical or contagious scrapie when appropriate evolutionary forces are in play. The study begins with an explanation of relevant evolutionary concepts such as evolvability and object of selection and proposes some explicit definitions of key terms such as variation, replication, heritability and strain. Observations of the behaviour of scrapie strains during serial passage in sheep, goats and mice assign the functions of variation, replication and heritability to the scrapie agent and establish it as an object of selection with a capacity for evolvability. Similar observations of strain behaviour in other prion diseases establish prions in general as objects of selection that are able to evolve. Accordingly, it is tenable that non-contagious atypical scrapie can provide progenitors for the prions causing contagious classical scrapie and can be a latent epidemiological threat. A comparison of atypical and classical scrapie identifies an affinity of the scrapie agent for lymphoreticular tissue and predilections for portals of exit and entry as key gain-of-function mutations that endow prion populations in atypical scrapie with the function of communicability or contagiousness. The present study can be seen as the hazard identification step within a process of risk analysis that systematises knowledge in aid of animal health and welfare and biosecurity. It justifies completion of the remaining steps in risk assessment. This task can be assisted by further comparisons of atypical and classical scrapie enlightened by historical records of scrapie disease, the epidemiology of atypical scrapie, the general behaviour of prions and evolutionary biology.
\end{abstract}

Keywords: Evolution, Prion, Risk, Scrapie, Sheep.

\section{Introduction}

Classical scrapie disease in domesticated sheep and goats and chronic wasting disease (CWD) in several species of wild-ranging deer possess the property of contagiousness or communicability and occur as propagating epidemics (Williams, 2005; Fast and Groschup, 2013). These features set them apart from other transmissible spongiform encephalopathies (TSEs) or prion diseases such as Creutzfeldt-Jakob disease (CJD) in humans, bovine spongiform encephalopathy (BSE) in cattle and atypical scrapie in sheep, which are transmissible only by artificial means and in contrived circumstances (Hörnlimann et al., 2006). Two strategically important questions arise from this crucial difference between classical scrapie and CWD compared with all other prion diseases including atypical scrapie. Firstly, how might a TSE or prion disease transform from being transmissible only in contrived conditions to being patently contagious and operating mechanisms for exit and entry of the causative agent? Secondly, can a non-contagious idiopathic form of scrapie (exemplified by atypical scrapie) be a predecessor to classical scrapie and a latent hazard that can convert to a contagious form under particular circumstances? Pursuit of these questions is impelled by a report from Portugal on two outbreaks of classical scrapie that were was related in time and place to a background incidence of atypical scrapie (Orge et al., 2010) and a case in Italy where the pathological features characteristic of classical scrapie and atypical (Nor98) scrapie were displayed simultaneously in a particular sheep (Mazza et al., 2010).

Evolutionary biology provides a means for addressing these two strategically important questions and the present study employs the fundamentals of evolution to clarify the case for evolvability in the scrapie agent and other prions. Evolvability refers to the capacity for something to possess and generate adaptive diversity and to evolve through natural selection (Kirschner and Gerhart, 1998; Brookfield, 2009) and the concept can extend to prions according to the 'extended evolutionary synthesis' (Pigliucci, 2009; Laland et al., 2015). The present study has risk analysis in mind (EFSA Scientific Committee, 2012) and is put forward as a hazard identification where the possibility that 
atypical scrapie is capable of evolving to classical scrapie may justify comprehensive risk assessment and preliminary guidelines for risk management. The intent is to provide a basis for (1) biosecurity measures against classical scrapie in places without the disease and (2) responses to occurrences of atypical scrapie and other sporadic prion disease of animals. A relevant example is the prion disease recorded in dromedary camels (Babelhadj et al., 2018).

\section{Natural selection and the scrapie agent}

Darwinian natural selection, the centrepiece of evolution, can be described by three inferences derived from five facts or postulates described by Mayr (2001) and then summed up in three key points (Campbell and Reece, 2002) as follows: (1) Natural selection is differential success in reproduction. (2) Natural selection occurs through an interaction between the environment and the variability inherent among individual organisms making up a population. (3) The product of natural selection is the adaptation of populations of organisms to their environment. These three points accord with the processes of variation, selection and inheritance that drive evolution (Maynard Smith, 1993) and with a depiction of evolution in biology as the 'changes in proportions of biological types in a population over time' (Millstein, 2017).

If a fundamental prerequisite is satisfied, the concepts of evolution and natural selection can apply to the scrapie agent and to prions in general. The scrapie agent, a prion or a protein that acquires alternative conformations that become self-propagating (Prusiner, 2013), is not an organism in the usual sense. However, the scrapie agent may fit as an as an object of selection (Lewontin, 1970; Mayr, 2001). Objects of selection variously labeled as units of selection (Lewontin, 1970), replicators (Dawkins, 1978), or selectons (Mayr, 1997) are natural entities that can evolve because they have three necessary capacities of variation, reproduction, and heritability (Lewontin, 1970; Hull, 1980). These capacities confer evolvability or the capacity to generate heritable, selectable phenotypic variation (Kirschner and Gerhart, 1998).

The case for the scrapie agent and prions being objects of selection requires an explanation of the three functions that define objects of selection. First, heritability in the biological, as opposed to the statistical sense, refers to the faithful transmission of characteristics through lineages of organisms, cells or molecules. Accordingly, species, groups, organisms, cells, genes and self-reproducing molecules such as prions can exhibit heritability. Second, the terms reproduction and replication are connected in that replication is fundamental to the biological processes of reproduction of organisms and the regeneration and repair of tissues and cells. Bonner (2007) refers to levels of reproduction starting with chemical replication and exemplified by the template replication of DNA, where one strand acts as a mould for another. An analogous process applies to prions, where normal cellular prion protein (PrPC) is converted to the diseased form of the prion protein (PrPSc) by a mechanism involving binding and templated misfolding (Colby and Prusiner, 2011; Jucker and Walker, 2013; Wenborn et al., 2015). Third, 'population' has the statistical meaning of 'an aggregate of creatures, things, cases and so on' (Campbell and Swinscow, 2009) and thus can apply to prions. These three explanations lend themselves to explicit or precising definitions that are appropriate and justifiable for the present study (Hurley, 2003).

Longstanding knowledge about scrapie in sheep (Parry, 1966, 1983) suggests that variation, replication and heritability function in the scrapie agent and make it an object of natural selection. Furthermore, observations on other prion diseases such as BSE (Konold et al., 2014) and CWD (Perrott et al., 2012) and on laboratory models of prion diseases in mice (Angers et al., 2010), hamsters (Kimberlin and Walker, 1978; Crowell et al., 2015) and bank voles (Watts et al., 2014) signal that prions in general classify as objects of natural selection. This preliminary knowledge confirms the utility of a detailed evaluation of evolvability in the scrapie agent and other prions and the applicability of intelligible concepts from evolutionary biology.

\section{Strains of the scrapie agent}

The explicit or precising definition of the term 'strain' used in the present study is adapted from that used for malaria (Hommel and Gilles, 1998). A precising definition suited to present purposes sees a strain as a population of communicable disease agents such as the scrapie agent (and other prions) derived from a particular source and possessing particular characteristics. Prion strains, including those involved in scrapie scrapie, may be differentiated according to their origin and seven criteria or particular characteristics (Groschup et al., 2006). These particular characteristics relate to behaviour and structure and consist of (1) disease symptomatology, (2) incubation period, (3) range of susceptible host species, (4) distribution and nature of lesions in the central nervous system, (5) resistance to different methods of inactivation, (6) resistance to digestion by proteinase-K digestion and sites of enzymatic cleavage, and (7) nature of glycosylation of the prion molecule (Collinge et al., 1996).

The history of scrapie strains and their seminal contribution to knowledge of prion diseases commences with studies on a primary isolate or passage line of scrapie obtained from sheep and known as SSBP/1 (sheep scrapie brain pool 1). SSBP/1 dates to 1945 and from a designed study in Scotland (Wilson $e t$ al., 1950), which extended the findings of Cuillé and 
Chelle (1938) that the scrapie agent can be transmitted from scrapie-infected to uninfected sheep by intracerebral inoculation with preparations of brain and spinal cord. Ten serial transmissions by Wilson et al. (1950) demonstrated that a pathogen with the functions of replication and heritability was a necessary cause of scrapie.

Dickinson (1976) recounted the subsequent history of SSBP/1 and reported that no noticeable changes in the clinical signs, incubation periods or in the relatively mild brain lesions were observed in experimentally infected sheep over 24 serial transmissions of SSBP/1. Experience since then confirms the heritable characteristics of the SSBP/1 strain as (1) clinical signs of fast onset, a short phase of ataxia and little pruritis, (2) a distinctive neuropathology with sparse vacuolation and differences in the distribution of PrPSc immunostaining in the brain compared with natural indigenous scrapie, and (3) differences in genetic resistance with sheep encoding at least one VRQ allele in their prion protein gene (PRNP) being susceptible to SSBP/1 and sheep encoding VRQ/VRQ and VRQ/ARQ being susceptible to indigenous natural scrapie (Foster et al., 2013). These attributes provided a reliable means for distinguishing SSBP/1 scrapie from indigenous natural scrapie and establishing that scrapie transmits prenatally and by embryo transfer (Foster et al., 2013). To clarify, notations ARQ and VRQ (plus AHQ, ARR and ARH) describe amino acid substitutions at codons 136, 154 and 171 of the ovine PRNP gene and haplotypes that are concerned with genetic resistance to classical scrapie (Dawson et al., 1998; Hunter and Bossers, 2007).

Other strains of the scrapie agent exhibit the functions of heritability and replication according to serial passage in sheep. One is $\mathrm{CH} 1641$, which was isolated in 1970 (Foster and Dickinson, 1988). CH1641 differs from SSBP/1 and indigenous natural scrapie (1) in not being transmissible to mice with different alleles of the gene controlling the scrapie incubation period (Foster and Dickinson, 1988), (2) in having a type $C$ as opposed to a type A or B glycoform pattern in its PrPSc (Hope et al., 1999), and (3) not being transmissible to sheep by the oral route (Arsac and Baron, 2014).

Another scrapie strain exhibiting the functions of heritability and replication is Nor98, which was first identified in Norway in 1998 (Benestad et al., 2003) and which can be considered a subgroup of atypical scrapie (Benestad and Bratberg, 2006). Nor98 has particularities as to clinical picture, genetic susceptibility, pathology and the nature of its PrPSc (Benestad and Bratberg, 2006) and, unlike SSBP/1 scrapie and indigenous natural scrapie, is not transmissible to the C57Bl, VM and RIII strains of inbred mice (Benestad et al., 2008). Nor98 tends to occur in older animals around six years of age, clinical signs can be subtle and vague. Signs include behavioural changes, emaciation and ataxia and circling but not pruritus or wool loss. Nor98 can be found in sheep with PrP genotypes that confer resistance to classical scrapie. The neuropathology seen in Nor98 differs from that seen in classical scrapie. In particular, the dorsal motor nucleus of the vagal nerve is unaffected; a finding of interest given that neuroinvasion by classical scrapie may involve the enteric nervous system (van Keulen et al., 2008). The PrPSc of Nor 98 is more susceptible to digestion by proteinase $\mathrm{K}$ and detection requires immunochemical methods with higher sensitivity than those for classical scrapie. Western blot profiles of Nor98 isolates show an additional band at around 11-12 kDa (Benestad and Bratberg, 2006).

Other scrapie strains come with sufficient information to demonstrate heritability and replication. Strains No. 13-7 and X124 were isolated from scrapie-infected sheep in the USA (Bulgin et al., 2006; Hamir et al., 2009) and are set apart by different genetic susceptibilities and incubation periods in sheep and different patterns of PrPSc accumulation (Moore et al., 2016). Variation among these five strains of the scrapie agent parallels longstanding knowledge about variation in the natural history of classical scrapie (Parry, 1966, 1983; Ulvund, 2006). Masujin et al. (2009) and Yokoyama et al. (2010) showed that brain homogenates from scrapie infected sheep contained more than one strain of scrapie and that prion strain selection occurs upon both inter- and intraspecies transmission.

\section{Variation in the scrapie agent}

The behaviour of scrapie strains upon serial passage in sheep assigns the functions of replication and heritability to the scrapie agent but does not demonstrate the capacity for variation. This third necessary function for evolvability is substantiated for the scrapie agent by records of the sub-passage of strains in species other than sheep.

Investigation of prion strains in laboratory animal models began when the SSBP/1 strain of scrapie was transmitted to goats by intracerebral injection and two disparate clinical pictures, 'drowsy' and 'scratching', emerged (Pattison and Millson, 1961). Twenty-five years later, Bruce and Dickinson (1987) could refer to the existence of 15 different strains of scrapie derived from a range of cases in sheep and goats and serially passaged in mice and usually via intracerebral inoculation. Strains were differentiated according to reproducible incubation periods in mice of defined genotypes and there was evidence for mutation in particular strains. These and more recent observations made with laboratory animal models of scrapie (Thackray et al., 2007, 2008, 2011, 2012) corroborate that scrapie strains possess functions of variation, 
replication and heritability and corroborate the scrapie agent as a unit or object of selection. Bruce and Dickinson (1987) applied knowledge existing at that time and argued that the scrapie agent must possess an independently replicating genome based on nucleic acids (the virino hypothesis). As stated earlier, chemical replication is now known to go beyond nucleic acid entities and extends to proteins by means the prion model of a misfolded self-propagating protein or protein aggregate (Uptain and Lindquist, 2002; Wickner et al., 2004; Halfmann and Lindquist, 2010).

\section{Evolvability of prions}

Observations on prion diseases other than scrapie and on the behaviour of their associated strains (Solforosi et al., 2013) point to mechanisms for evolvability that render prions objects of selection. Angers et al. (2010) identified two strains of the CWD agent according to their incubation times and neuropathology in mice and used differences between deer species to demonstrate that strain selection and mutation was influenced by residue 226 of the prion protein gene. Li et al. (2010) and Mahal et al. (2010) studied prion strains in cultures of murine cell lines and showed that treatment with swainsonine (an inhibitor of glycoprotein processing) led to heritable changes in the phenotypic properties of prions that could be selectively amplified. Prion populations responded in accord with the processes of natural selection and variants replicating most abundantly in particular circumstances eventually became dominant.

Similar observations of natural selection have been made with prions in a variety of situations (Ghaemmaghami et al., 2011, 2013; Vulin et al., 2012; Crowell et al., 2015). Collinge (2016) encapsulated prions as a 'dynamic collection or cloud of misfolded protein assemblies' that are maintained under biological selection in a host, and its constituent tissues' and existing as distinct strains with an ability to adapt and mutate.

The depiction of prions as objects of selection equipped for variation, replication and heritability is well grounded and justifies the thesis that non-contagious atypical scrapie is a prospective epidemiological threat that can provide progenitors for the prions causing contagious classical scrapie. Appraisal of this thesis can be assisted by a comparison of the characteristics of atypical and classical scrapie and an exploration of possible cellular and molecular mechanisms underlying the genesis of atypical scrapie and possibilities for transformation to a communicable version of the disease.

\section{Comparison of atypical and classical scrapie}

Classical scrapie, as opposed to the entity known as atypical scrapie, has epidemic potential. The Panel on Biological Hazards of the European Food Safety Authority expresses a consensus view that atypical scrapie 'does not present, epidemiologically, like an infectious disease' (EFSA Panel on Biological Hazards, 2014). This wording allows for the present approach, which envisages two forms of scrapie. One, represented by atypical scrapie, is an idiopathic noncontagious form of the disease disease. The other, represented by classical scrapie, is a contagious form of the disease. An understanding of this crucial difference in contagiousness or communicability may come from a comparison of the characteristics of classical and atypical scrapie (including Nor98 scrapie) according to PRNP genotypes affected, age of onset of the disease, symptomatology, disease duration, neuropathological features, tissue distribution of PrPSc and infectivity, resistance of PrPSc to protease digestion and glycoform pattern.

Table 1 shows that the characteristics listed above differ between classical and atypical scrapie and that differences occur at each level in the hierarchy of biological organisation from molecule to organism. Some characteristics overlap between classical and atypical scrapie and others show clear demarcations. Overlaps may signify differing frequencies of variants within population of prions involved in classical and atypical scrapie and imply scope for natural selection. Clear demarcations between sets of characteristics may signify where gains-of-function in prion populations are required for atypical scrapie to become contagious. Genotypes of the PRNP gene explored in relation to either classical scrapie or atypical scrapie have fundamentally different implications for pathogenesis. In the case of classical scrapie, the fifteen genotypes classified into five types within the National Scrapie Plan for Great Britain and other control programs (Hunter and Bossers, 2007) link to a gradient of resistance against infection resulting from environmental exposure to the scrapie agent. By contrast, the genotypic associations for atypical scrapie connect to a situation involving the de novo and endogenous generation of disease. Atypical scrapie has been seen most frequently in sheep with PRNP genotypes tending towards resistance against classical scrapie (Benestad et al., 2008).

High prevalences of atypical scrapie have been observed in sheep with the AHQ/AHQ genotype (Arsac et al., 2007; McIntyre et al., 2008) and in sheep with particular polymorphisms at codon 141 of the PRNP gene (Moum et al., 2005).

Characters of classical scrapie and atypical scrapie that differ in degree rather than kind are age of onset of disease, duration of disease and symptomatology. Differences in these characters can be explained according to the concept of strain diversity in prions (Collinge, 2016) and attributed in part to the action of variants within the particular population of prions operating in an individual host. 
Table 1. Characteristics of classical scrapie and atypical scrapie (including disease caused by the Nor98 agent) (from Parry, 1983; Benestad and Bratberg, 2006; Hörnlimann et al., 2006; Ulvund, 2006, 2008; Benestad et al., 2008; Wemheuer et al., 2011; Fast and Groschup, 2013).

\begin{tabular}{|c|c|c|}
\hline Characters & Classical Scrapie & Atypical scrapie (including Nor98 scrapie) \\
\hline Ovine genotypes affected* & $\begin{array}{l}\text { VRQ and ARQ haplotypes most susceptible. } \\
\text { ARR most resistant. }\end{array}$ & $\begin{array}{l}\text { Nor } 98 \text { can occur in ARR genotypes. High } \\
\text { incidence of atypical scrapie in AHQ genotype } \\
\text { and low incidence in ARQ genotype. }\end{array}$ \\
\hline $\begin{array}{l}\text { Age of onset of natural } \\
\text { disease }\end{array}$ & $\begin{array}{l}\text { Between } 2 \text { and } 5 \text { years of age with average } \\
\text { age } 3.5 \text { years }\end{array}$ & On average 6.5 years old. \\
\hline Duration of disease & 2 weeks to 6 months to death, rarely longer & 6 weeks to 8 months to death \\
\hline Symptomatology & $\begin{array}{l}\text { Behavioural change, tremour, pruritus and } \\
\text { locomotor disorder. }\end{array}$ & $\begin{array}{l}\text { Weight loss, behavioural change (nervousness, } \\
\text { anxiety), tremour infrequent, pruritus not } \\
\text { observed, and locomotor disorder (ataxia, } \\
\text { circling). }\end{array}$ \\
\hline $\begin{array}{l}\text { Nature and tissue distribution } \\
\text { of } \operatorname{PrP}^{S c} \text { and infectivity }\end{array}$ & $\begin{array}{l}\mathrm{PrP}^{\mathrm{Sc}} \text { and infectivity occurs as constant } \\
\text { feature in peripheral lymphoid tissue. }\end{array}$ & $\begin{array}{l}\mathrm{PrPSc} \text { not detected outside the central nervous } \\
\text { system or in the peripheral lymphoid tissue. } \\
\text { Infectivity detected in lymphoid tissue, nerves, } \\
\text { and muscles by bioassay with transgenic mice. }\end{array}$ \\
\hline $\begin{array}{l}\text { Nature and distribution of } \\
\text { lesions in the central nervous } \\
\text { system }\end{array}$ & $\begin{array}{l}\text { Lesions in grey matter include vacuolation, } \\
\text { neuronal loss and occasional astrocytosis. } \\
\text { Lesions predominate in brainstem and occur } \\
\text { at the level of the obex. Distribution of } \\
\text { lesions in more rostral areas of the brain } \\
\text { varies widely. }\end{array}$ & $\begin{array}{l}\text { Vacuolated grey matter predominates in the } \\
\text { molecular layer of the cerebellar cortex and } \\
\text { also occurs more rostrally in the basal ganglia } \\
\text { and cerebral cortex, Brainstem lesions are } \\
\text { insubstantial and no lesions are observed at the } \\
\text { obex. }\end{array}$ \\
\hline $\begin{array}{l}\text { Nature and distribution of } \\
\operatorname{PrP}^{\mathrm{Sc}} \text { deposits in central } \\
\text { nervous system }\end{array}$ & $\begin{array}{l}\mathrm{PrP}^{\mathrm{Sc}} \text { occurs intra- and perineuronally, in } \\
\text { association with glia and elsewhere. } \mathrm{PrP}^{\mathrm{Sc}} \\
\text { deposits are a constant feature in caudal } \\
\text { brainstem, mainly at the level of the obex } \\
\text { and the dorsal motor nucleus of the vagus } \\
\text { nerve (DMNV). Extent of } \mathrm{PrP}^{\mathrm{Sc}} \text { deposits } \\
\text { depends on progression of disease and } \\
\text { occurs throughout the CNS at clinical } \\
\text { endpoint. }\end{array}$ & $\begin{array}{l}\text { No PrP } \mathrm{P}^{\mathrm{Sc}} \text { in neurons. } \mathrm{PrP}^{\mathrm{Sc}} \text { deposits mainly in } \\
\text { the cerebellar cortex (especially in the } \\
\text { molecular layer), cerebral cortex and basal } \\
\text { ganglia, in the spinal tract nucleus of the } \\
\text { trigeminal nerve, and within white matter } \\
\text { throughout the brain. Dorsal motor nucleus of } \\
\text { the vagus nerve (DMNV) without PrPSc. }\end{array}$ \\
\hline Immunoblot pattern & $\begin{array}{l}\text { Three bands indicating unglycosylated, } \\
\text { monoglycosylated and diglycosylated } \mathrm{PrP}^{\mathrm{Sc}} \\
\text { with molecular masses between } 18 \text { and } 30 \\
\text { kDa. }\end{array}$ & $\begin{array}{l}\text { Four bands: Three indicate unglycosylated, } \\
\text { monoglycosylated and diglycosylated PrPSc } \\
\text { with molecular masses between } 18 \text { and } 30 \mathrm{kDa} \text {. } \\
\text { A fourth band occurs below } 15 \mathrm{kDa} \text {. }\end{array}$ \\
\hline $\begin{array}{l}\text { Transmissibility to } \\
\text { transgenic mice }\end{array}$ & Yes & Yes \\
\hline
\end{tabular}

As to age of onset, classical scrapie has been observed in the field in sheep from 1 to 11 years of age (Parry, 1983) and occurs most frequently in sheep between 2 and 5 years of age and at an average age of 3.5 years (Parry, 1983; Ulvund, 2008). Age of onset of classical scrapie varies from flock to flock. For example, McIntyre et al. (2008) recorded means from 30 flocks that ranged from 2.0 to 5.7 years. For atypical scrapie, Ulvund points to 84 cases from nine different countries that record ages and the mean age was 6.5 years. Lühken et al. (2007) analysed reports of scrapie in sheep in Germany between January 2002 and February 2006 and found that 2 out of 20 cases $(10 \%)$ of classical scrapie and 35 out of $60(58 \%)$ cases of atypical scrapie occurred in sheep older than 5 years. Fediaevsky et al. (2008) analysed data obtained between 2002 and 2006 from 20 European countries under the European
Union's active surveillance program for TSE in sheep and found that 127 out of 256 or $24 \%$ of cases of classical scrapie and 231 out of 329 or $70 \%$ cases of atypical scrapie occurred in sheep older than 5 years. In short, atypical scrapie tends to occur in older sheep and differs from classical scrapie in this respect. The occurrence in older sheep may reflect an aetiology related to host and environmental factors not exogenous infection as in classical scrapie. As to symptomatology, a thumbnail description of scrapie states that 'the disease is recognised by the clinical signs, which are variable, but generally start insidiously with behavioural abnormalities then progress to more obvious neurological signs, including pruritus and incoordination.

Affected animals have poor body condition' (OIE, 2017). Ulvund $(2006,2008)$ listed 33 different clinical 
signs of scrapie from four different scientific reports and clustered them under headings of 'general signs', 'changes in behavior', 'changes in sensitivity', 'changes in locomotion' and 'other signs'. Ataxia and head tremor were the initial most dominating signs in Ireland, while altered mental status, pruritus and wool loss were the initial most dominant signs among Norwegian and Spanish sheep.

In Italian sheep, both ataxia and pruritus were seen frequently. Parry (1966) used over 1,200 individual clinical records to classify the clinical expression of scrapie into five typical syndromes of 'classical' natural scrapie and five atypical syndromes of scrapie-like illness in sheep.

Scrapie in sheep has a remarkably diverse symptomatology that varies with flock, breed, and region and points to factors in the host (genotype), disease agent (scrapie strain) and environment (unknown). On this point, the clinical signs of atypical scrapie in Norway were ataxia, anxiety and loss of body condition.

Overt pruritus has not been reported but the scratch reflex has (Konold et al., 2007) and may represent nascent pruritus. The clinical signs in atypical scrapie have a pattern that may signal the frequency and properties of certain prion variants in a particular strain and imply scope for selection. The same consideration applies to the duration of disease and its termination in death.

Characteristics of classical scrapie and atypical scrapie that differ in kind as opposed to degree are (1) the tissue distribution of PrPSc and infectivity, (2) the nature and distribution of lesions and PrPSc deposits in the central nervous system, and (3) the immunoblot pattern. These differences align with capabilities present in contagious classical scrapie but absent from atypical scrapie. Contagion in scrapie will be precluded if prions are restricted to the central nervous system and have no access to the portals of exit known to be involved in scrapie transmission.

Once again, differences between atypical and classical scrapie can be attributed to diversity among and within prions strains. Furthermore, the accompanying ability of prion strains to adapt and mutate (Collinge, 2016) provides a mechanism for gains and losses of function, the acquisition of missing capabilities and the emergence of contagious forms of scrapie.

Several studies have failed to detect PrPSc in peripheral lymphoid tissue in cases of atypical/Nor98 scrapie. This finding is consistent with a spontaneous origin of PrPSc in the brain but could also indicate that ingested PrPSc may bypass the lymphoid system en route to the brain (reviewed in Benestad et al., 2008).

The situation has been clarified by highly sensitive transmission studies with transgenic mice overexpressing the VRQ allele of the ovine PRNP gene.
Such transmission studies have detected infectivity in lymphoid tissues, nerves, and muscles in natural cases of atypical/Nor 98 scrapie and also in atypical/Nor98 scrapie induced by intracerebral inoculation (Andreoletti et al., 2011).

The appearance of infectivity in peripheral tissues following the induction of disease by intracerebral inoculation indicates that infectivity outside the central nervous system originates from infectivity inside the central nervous system.

In natural cases of atypical scrapie, it is conceivable that prions may form de novo both inside and outside the central nervous system. Intracerebral injection causes extensive local hemorrhage and tissue necrosis and leakage of inoculum into the ventricles and meninges (Hamir et al., 2002).

The tissue reactions involved would escalate the normal drainage of interstitial fluid to peripheral tissue via the vascular, glial, and lymphatic immune pathways described for the central nervous system (Weller et al., 2009; Aspelund et al., 2015; Engelhardt et al., 2016). This drainage, as it occurs normally, can be proposed as a route of exit of prions from the central nervous system in naturally occurring atypical scrapie.

Regardless of possible origin, scrapie prions that occur outside the central nervous system in cases of atypical scrapie constitute a population in which mutation and selection may lead to new and contagious strains of the scrapie agent. A crucial gain-of-function would be increased affinity by the scrapie agent for the lymphoreticular system. The consequential migratory and circulatory activity of lymphocytes and mononuclear phagocytes would distribute infectivity throughout the body and transfer it to and from prenatal and post-natal portals of exit and entry.

Predilections for particular portals of exit may be another important gain-of-function in the possible evolution of contagious strains of scrapie. In this connection, portals of exit demonstrated for the scrapie agent in sheep include excretions and ejecta such as faeces (Everest et al., 2011; Terry et al., 2011), urine (Ligios et al., 2007; Rubenstein et al., 2011), and foetal membranes (Pattison et al., 1972, 1974; Onodera et al., 1993; Race et al., 1998; Tuo et al., 2001, 2002; Andreoletti et al., 2002; Alverson et al., 2006; Lacroux et al., 2007); and secretions such as milk (Konold et al., 2008, 2013; Lacroux et al., 2008; Maddison et al., 2009; Ligios et al., 2011), oral secretions (Vascellari et al., 2007; Maddison et al., 2010; Gough et al. 2012) and semen (Rubenstein et al., 2012).

Transmission routes that operate via reproductive processes in sheep may be pre-eminent in the acquisition of communicability by prion populations in atypical scrapie. Reproductive processes provide exceptional exposure to infection that is determined anatomically and physiologically. 


\section{Discussion}

Evolutionary biology is highly relevant to the health of animals, people and all living systems (LeGrand and Brown, 2002; Nesse and Stearns, 2008; Gluckman et al., 2009; Omenn, 2010) and has been proposed as a basic science for medicine (Nesse et al., 2010). The discipline facilitates an understanding of the dynamics of the interactions between host and pathogen (Ewald, 1994), the interplay between immunity and infectious disease agents (Frank, 2002), resistance to antimicrobial and antiparasitic agents (Waller, 1997; Baquero et al., 2015) and pesticides (Georghiou, 1972), the emergence of previously unknown pathogens (Morse, 1995) and the generation of new strains of known pathogens, particularly viruses (Holmes, 2013). Evolutionary biology has been used in the present study in relation to risk assessment and to investigate the proposition that non-contagious atypical scrapie has an inbuilt potential for acquiring the function of communicability and is capable of transforming to classical contagious scrapie. The conclusion is that atypical scrapie, proposed as an idiopathic noncontagious form of scrapie, can be classified as a latent hazard for contagious scrapie, typified by the classical form of the disease. Reasons for this conclusion and its implications for risk management are reviewed according to developments in evolutionary biology and an explanation of how the concepts of evolutionary biology were applied.

As to developments in evolutionary biology, Futuyma (1988) describes the history of evolutionary thought and highlights the 'modern synthesis' that arose in the 1930s. The modern synthesis 'forged the contributions from of genetics, systematics, and paleontology into a new neo-Darwinian theory that reconciled Darwin's theory with the facts of genetics (Mayr and Provine, 1980)'. The 'extended evolutionary synthesis' has now appeared (Jablonka and Lamb, 2005; Noble et al., 2014; Pigliucci and Finkelman, 2014; Laland, et al., 2015) and is seen as an augmentation to the modern synthesis, which has 'a more inclusive conceptual framework' embracing matters such as 'an expanded theory of heredity, elements of complexity theory, ideas about evolvability, and a reevaluation of levels of selection' (Pigliucci, 2009). Jablonka and Lamb (2005) refer specifically to prions in their discussion of a new synthesis. The current study deals with the basic functions that drive evolution and not the underlying molecular mechanisms. Accordingly, both perspectives on evolution support the current finding that atypical scrapie is a latent hazard for classical scrapie. However, the extended synthesis is not restricted to genomes based on RNA and DNA and can allow use of the wellfounded protein-only prion theory (Colby and Prusiner, 2011; Soto, 2011) to explore the natural history of classical and atypical scrapie and provide a clearer view of future developments. The concept of evolvability was central to the present investigation and readily identified atypical scrapie as a possible predecessor to classical scrapie and a latent hazard that can convert to a contagious form under particular circumstances. Evolvability builds on the notions of variation, selection and inheritance that drive evolution (Maynard Smith, 1993) and refers to the capacity by which something possesses and generates adaptive diversity and evolves through natural selection (Kirschner and Gerhart, 1998; Brookfield, 2009). Living systems or their parts that display evolvability qualify as objects or units of selection (Mayr, 2001).

Application of evolvability in the present study required explicit or precising definitions for the terms heritability, replication/reproduction, population and strain. Precising definitions were also formulated for classical scrapie and atypical scrapie. Precising definitions clarify terms used in systematic endeavours such as science and are required to be appropriate and legitimate for the context in which they are employed (Hurley, 2003). Thus, heritability refers to the faithful transmission of characteristic through lineages of organisms, cells or molecules. The terms reproduction and replication had their usual meaning but can occur at all levels of biological organisation beginning with molecules. Variation required no qualification beyond its usual meaning. Population had the statistical meaning of an aggregate of creatures, things, cases and so on. A strain was defined as a population of communicable disease agents such as the scrapie agent (or other prions) derived from a particular source and possessing particular characteristics.

Transmission studies with scrapie strains in sheep, goats and laboratory animals demonstrate that the scrapie agent possesses functions of variation, replication and heritability and substantiate plausible predictions of evolvability allowed by the natural history of the disease. Similar transmission studies with prion strains in other animals (Solforosi et al., 2013; Collinge, 2016) indicate that prions as a class possess capabilities for variation, replication and heritability, are thus evolvable and qualify as objects of selection. Confirmation of heritability and replication for the scrapie agent came from Wilson et al. (1950) starts with a report of ten serial passages of the SSBP/1 strain (sheep scrapie brain pool 1). Dickinson (1976) reported a total of 24 serial passages of SSBP/1, which showed consistency in clinical signs, incubation period and brain pathology. Foster et al. (2013) added genetic resistance and the distribution of PrPSc immunostaining to the list of heritable characters in the SSBP/1 strain. Since then, serial transmission studies with four more strains of the scrapie agent have corroborated the functions of heritability and replication; CH1461 (Foster and Dickinson, 1988; 
Hope et al., 1999; Arsac and Baron, 2014), Nor98 (Benestad et al., 2003; Benestad and Bratberg, 2006) and scrapie isolates, No. 13-7 and x124 (Bulgin et al., 2006; Hamir et al., 2009; Moore et al., 2016). Variation, the third capability or function making for evolvability, is substantiated for the scrapie agent by studies of strains in species other than sheep. Two substrains, 'drowsy' and 'scratching', were identified by transmission of SSBP/1 in goats (Pattison and Millson, 1961). Bruce and Dickinson (1987) described the characteristics of 15 different strains of scrapie derived from a range of cases in sheep and goats and serially passaged in mice and pointed to evidence for mutation in some strains. More recent observations with laboratory animal models of scrapie (Thackray et al., 2007, 2008, 2011, 2012) add further support that the scrapie agent possesses functions of variation, replication and heritability and qualifies as a unit or object of selection.

Observations with other prion diseases establish that prions as a class are evolvable. Selection and mutation has been demonstrated with strains of the CWD agent (Angers et al., 2010). Li et al. (2010) and Mahal et al. (2010) used a chemical agent (swainsonine) to induce mutation in prion strains passaged in mouse cell lines and produced heritable changes that could be amplified by selection. Other evidence for variation, selection and inheritance in populations of prions comes from for the operation of natural selection in prion populations (Ghaemmaghami et al., 2011, 2013; Vulin et al., 2012; Crowell et al., 2015). Collinge (2016) draws a parallel between the quasispecies concept for viruses and the behaviour of prion strains and their molecular diversity. In short, the quasispecies concept seeks to highlight the diversity and high rate of mutation that can occur within a virus species and the selection of variants most fitted to a host (Heise and Virgin, 2013; Holmes, 2013). Flint et al. (2015) describe quasispecies as virus populations that exist as dynamic distributions of nonidentical but related replicons. The term replicon is used in molecular biology to refer to 'any DNA (or RNA) molecule that is capable of surviving and replicating itself in a cell' (Clark and Pazdernik, 2013) and the nub of the term can be regarded as the capacity of a molecular entity to replicate. Since the scrapie agent and prions in general are able to replicate, they qualify as replicons. Analogies with viral evolution may thus have value in future studies on the possible transformation of non-contagious scrapie to contagious scrapie. The present study has combined reasoning from evolutionary biology and evidence from the scientific literature to establish the scrapie agent and other prions as objects of selection and to conclude that atypical or non-contagious scrapie is capable of transforming to classical or contagious scrapie in particular unknown circumstances. As a consequence, the present study qualifies as a hazard identification step within processes of risk analysis that can systematize scientific knowledge for animal health, welfare and biosecurity (FAO, 2007). A comparison these processes (EFSA, 2012) suggests that the model used by the Codex Alimentarius Commission (CAC), rather those of the World Organisation for Animal Health (OIE) or the International Plant Protection Convention (IPCC), can cover most needs in relation to animal health. The CAC model consists of a cycle or sequence of risk assessment, risk management and risk communication that builds around the distinction between "hazard" and "risk" (CAC, 2015). Here, a hazard is seen as a biological, chemical or physical agent or condition with the potential to cause harm and risk is an estimate of the probability and severity of the adverse health effects (FAO, 1997).

Identification of atypical or non-contagious scrapie as a hazard for classical or contagious scrapie provides grounds for undertaking the remaining steps in risk assessment. The concern is that the scrapie agent and prions in general are established as evolvable and that atypical non-contagious scrapie can lead to local and endogenously derived outbreaks of classical contagious scrapie when a particular set of causal factors coincide. These causal factors include capabilities for operating portals of exit and entry from one animal to another and predilections for lymphoreticular tissue as described the present comparison of atypical and classical scrapie. The remaining steps in risk assessment are hazard characterisation, exposure assessment and risk characterisation and their completion can be assisted by (1) further comparisons of of atypical and classical scrapie , (2) exploring possible cellular and molecular mechanisms underlying the genesis of atypical scrapie and possibilities for transformation to a communicable version of the disease, (3) searching the historical record of scrapie disease in sheep for indications of an independent appearance of scrapie at different times and in different places, and (4) investigating reports on epidemiological aspects of atypical and Nor98 strain scrapie. The discipline of evolutionary biology has an expanding role in public health and comparative medicine (Nesse and Stearns, 2008; Nesse et al., 2010). It has been decisive in the present study and can have further application in a full risk assessment on the possible transformation of atypical scrapie to classical scrapie. A full risk assessment will allow the drafting of anticipatory risk management measures that are based on the best available knowledge and are open to advances in knowledge. The endogenous generation of epidemics of classical contagious scrapie from sources in atypical scrapie may be extremely rare. However, biosecurity strategies based solely on preventing transboundary incursions of classical scrapie can no longer be regarded as comprehensive. 


\section{Conflict of interest}

The author declares that there is no conflict of interest.

\section{References}

Alverson, J., O’Rourke, K.I. and Baszler, T.V. 2006. PrPSc accumulation in fetal cotyledons of scrapieresistant lambs is influenced by fetus location in the uterus. J. Gen. Virol. 87, 1035-1041.

Andreoletti, O., Orge, L., Benestad, S.L., Beringue, V., Litaise, C., Simon, S., Le Dur, A., Laude, H., Simmons, H., Lugan, S., Corbiere, F., Costes, P., Morel, N., Schelcher, F. and Lacroux, C. 2011. Atypical/Nor98 scrapie infectivity in sheep peripheral tissues. PLoS Pathogens. 7, e1001285. doi: 10.1371/journal.ppat.1001285.

Andreoletti, O., Lacroux, C., Chabert, A., Monnereau, L., Tabouret, G., Lantier, F., Berthon, P., Eychenne, F., Lafond-Benestad, S., Elsen, J.M. and Schelcher, F. 2002. PrPSc accumulation in placentas of ewes exposed to natural scrapie: influence of foetal PrP genotype and effect on ewe-to-lamb transmission. J. Gen. Virol. 83, 2607-2616.

Angers, R.C., Kang, H.E., Napier, D., Browning, S., Seward, T., Mathiason, C., Balachandran, A., McKenzie, D., Castilla, J., Soto, C., Jewell, J., Graham, C., Hoover, E.A. and Telling, G.C. 2010. Prion strain mutation determined by prion protein conformational compatibility and primary structure. Science 328, 1154-1158.

Arsac, J.N. and T. Baron. 2014. Distinct transmissibility features of TSE sources derived from ruminant prion diseases by the oral route in a transgenic mouse model (TgOvPrP4) overexpressing the ovine prion protein. PLoS One. 9, e96215.

Arsac, J.N., O. Andreoletti, J.M. Bilheude, C. Lacroux, S.L. Benestad, T. and Baron. 2007. Similar biochemical signatures and prion protein genotypes in atypical scrapie and Nor98 cases, France and Norway. Emerg. Infect. Dis. 13, 58-65.

Aspelund, A., Antila, S., Proulx, S.T., Tine, V.K., Karaman, S., Detmar, M., Wiig, H. and Alitalo, K. 2015. A dural lymphatic vascular system that drains brain interstitial fluid and macromolecules. J. Exp. Med. 212, 991-999.

Babelhadj, B., Di Bari, M.A., Pirisinu, L., Chiappini, B., Gaouar, S.B.S., Riccardi, G., Marcon, S., Agrimi, U., Nonno, R. and Vaccari, G. 2018. Prion disease in dromedary camels, Algeria. Emerg. Infect. Dis. 24, 1029-1036.

Baquero, F., Lanza, V.F., Cantón, .R and Coque, T.M. 2015. Public health evolutionary biology of antimicrobial resistance: priorities for intervention. Evol. Appl. 8, 223-39.

Benestad, S.L., Sarradin, P., Thu, B., Schonheit, J., Tranulis, M.A. and Bratberg, B. 2003. Cases of scrapie with unusual features in Norway and designation of a new type, Nor98. Vet. Rec. 153, 202-208.

Benestad, S.L. and Bratberg, B. 2006. Atypical scrapieNor98. In Prions in Humans and Animals, Eds. Hörnlimann, B., Riesner, D. and Kretschmar, H. Berlin: De Gruyter, pp: 630-634.

Benestad, S.L., Arsac, J.N., Goldmann, W. and Noremark, M. 2008. Atypical/Nor98 scrapie: properties of the agent, genetics, and epidemiology. Vet. Res. 39, 19.

Bonner, J.T. 2007. General Features of Reproduction. In Volume 26 Encyclopædia Britannica $15^{\text {th }} \mathrm{Ed}$. Chicago: Encyclopædia Britannica Inc. pp: 609612.

Brookfield, J.F.Y. 2009. Evolution and evolvability: celebrating Darwin 200. Biol. Lett. 5, 44-46.

Bruce, M.E. and Dickinson, A.G. 1987. Biological evidence that scrapie agent has an independent genome. J. Gen. Virol. 68, 79-89.

Bulgin, M.S., Sorensen ,S.J. and Matlock, M.E. 2006. Association between incubation time and genotype in sheep experimentally inoculated with scrapiepositive brain homogenate. Am. J. Vet. Res. 67, 498-504.

CAC (Codex Alimentarius Commission). 2015. Procedural Manual, Twenty Fourth Edition. Joint FAO/WHO Food Standards Programme. Rome: World Health Organization Food and Agricultural Organization of the United Nations.

Campbell, M.J. and Swinscow, T.D.V. 2009. Statistics at Square One. Oxford: BMJ Publishing Group Limited and John Wiley and Sons Limited.

Campbell, N.A. and Reece, J.B. 2002. Biology, $6^{\text {th }}$ Ed. San Francisco: Benjamin Cummings.

Clark, D.P. and Pazdernik, N.J. 2013. Molecular Biology, 2nd Ed. Amsterdam: Elsevier.

Colby, D.W. and Prusiner, S.B. 2011. Prions. Cold Spring Harb. Perspect. Biol. 3, a006833.

Collinge, J. 2016. Mammalian prions and their wider relevance in neurodegenerative diseases. Nature 539, 217-226.

Collinge, J., Sidle, K.C., Meads, J., Ironside, J. and Hill, A.F. 1996. Molecular analysis of prion strain variation and the aetiology of 'new variant' CJD. Nature 383, 685-690.

Crowell, J., Hughson, A., Caughey, B. and Bessen, R.A. 2015. Host determinants of prion strain diversity independent of prion protein genotype. Molecular Bilology, Second Edition J. Virol. 89, 10427-10441.

Cuillé, J. and Chelle, P.L. 1938. La tremblante du mouton est bien inoculable. C. R. Acad. Sci. (Paris) 206, 78-79.

Dawkins, R. 1978. Replicator selection and the extended phenotype. Z. Tierpsychol. 47, 61-76. 
Dawson, M., Hoinville, L.J., Hosie, B.D. and Hunter, N. 1998. Guidance on the use of PrP genotyping as an aid to the control of clinical scrapie. Scrapie Information Group. Vet. Rec. 142, 623-625.

Dickinson, A.G. 1976. Scrapie in sheep and goats. In Slow Virus Disease of Animals and Man. Ed., Kimberlin, R.H. Amsterdam: North-Holland Publishing Company, pp: 209-241.

EFSA Panel on Biological Hazards. 2014. Scientific opinion on the scrapie situation in the EU after 10 years of monitoring and control in sheep and goats. EFSA Journal 12, 3781.

EFSA Scientific Committee. 2012. Scientific Opinion on Risk Assessment Terminology. EFSA Journal 10, 2664.

Engelhardt, B., Carare, R.O., Bechmann, I., Flugel, A., Laman, J.D. and Weller, R.O. 2016. Vascular, glial, and lymphatic immune gateways of the central nervous system. Acta. Neuropathol. 132, 317-338.

Everest, S.J., Ramsay, A.M., Chaplin, M.J., Everitt, S., Stack, M.J., Neale, M.H., Jeffrey, M.S., Moore, J.S., Bellworthy, J. and Terry, L.A. 2011. Detection and localisation of PrP in the liver of sheep infected with scrapie and bovine spongiform encephalopathy. PLoS One 6, e19737.

Ewald, P.W. 1994. Evolution of Infectious Disease. Oxford: Oxford University Press.

FAO. 1997. Risk Management and Food Safety. FAO Food and Nutrition Paper No. 65. Rome: Food and Agriculture Organization of the United Nations.

FAO. 2007. Biosecurity Toolkit. Rome: Food and Agriculture Organization of the United Nations.

Fast, C. and Groschup, M.H. 2013. Classical and atypical scrapie in sheep and goats. In Prions and Diseases, Volume 2, Animals, Humans and the Environment. Eds. Zou, W-Q. and Gambetti. P. New York: Springer, pp: 15-44.

Fediaevsky, A., Tongue, S.C., Noremark, M., Calavas, D., Ru, G. and Hopp, P. 2008. A descriptive study of the prevalence of atypical and classical scrapie in sheep in 20 European countries. BMC Vet. Res. 4, 19.

Flint, J., Racaniello, V.R., Rall, G.F., Skalka, M.S. and Enquist, L.W. 2015. Principles of Virology, $4^{\text {th }} \mathrm{Ed}$. Washington DC: American Society for Microbiology.

Foster, J.D. and Dickinson, A.G. 1988. The unusual properties of $\mathrm{CH} 1641$, a sheep-passaged isolate of scrapie. Vet. Rec. 123, 5-8.

Foster, J.D., Goldmann, W. and Hunter, N. 2013. Evidence in sheep for pre-natal transmission of scrapie to lambs from infected mothers. PLoS One 8, e79433.

Frank, S.A. 2002. Immunology and Evolution of Infectious Disease. Princeton University Press, Princeton and Oxford.
Futuyma, D.J. 1988. Evolutionary Biology, 2nd Ed. Sunderland, Massachusetts: Sinauer Associates Inc..

Georghiou, G.P. 1972. The evolution of resistance to pesticides. Ann. Rev. Ecol. Syst. 3, 133-168.

Ghaemmaghami, S., Colby, D.W., Nguyen, H.O., Hayashi, S., Oehler, A., DeArmond, S.J. and Prusiner, S.B. 2013. Convergent replication of mouse synthetic prion strains. Am. J. Pathol. 182, 866-874.

Ghaemmaghami, S., Watts, J.C., Nguyen, H.O., Hayashi, S., DeArmond, S.J. and Prusiner, S.B. 2011. Conformational transformation and selection of synthetic prion strains. J. Mol. Biol. 413, 527542.

Gluckman, P., Beedle, A. and Hanson, M. 2009. Principles of Evolutionary Medicine. Oxford: Oxford University Press.

Gough, K.C., Baker, C.A., Rees, H.C., Terry, L.A., Spiropoulos, J., Thorne, L. and Maddison, B.C. 2012. The oral secretion of infectious scrapie prions occurs in preclinical sheep with a range of PRNP genotypes. J. Virol. 86, 566-571.

Groschup, M.H., Gretzschel, A. and Kuczius, T. 2006. Prion strains In Prions in Humans and Animals, Eds. Hörnlimann, B., Riesner, D. and Kretschmar, H. Berlin: De Gruyter, pp: 166-186.

Halfmann, R. and Lindquist, S. 2010. Epigenetics in the extreme: prions and the inheritance of environmentally acquired traits. Science 330, 629632.

Hamir, A.N., Kunkle, R.A., Richt, J.A., Greenlee, J.J. and Miller, J.M. 2009. Serial passage of sheep scrapie inoculum in Suffolk sheep. Vet. Pathol. 46, 39-44.

Hamir, A.N., Miller, J.M., Stack, M.J. and Chaplin, M.J. 2002. Failure to detect abnormal prion protein and scrapie-associated fibrils 6 wk after intracerebral inoculation of genetically susceptible sheep with scrapie agent. Can. J. Vet. Res. 66, 289294.

Heise, M.T. and Virgin, H.W. 2013. Pathogenesis. In: Fields Virology, 6th Ed. Eds: Knipe, D.M. and Howling, P.M. Philapelphia: Lippincott Williams and Wilkins, pp: 254-285.

Holmes, E.C. 2013. Evolution. In: Fields Virology, Sixth Edition. Eds: Knipe, D.M. and Howling, P.M. Philadelphia: Lippincott Williams and Wilkins. pp. 286-313.

Hommel, M. and Gilles, H.M. 1998. Malaria. In Topley and Wilson's Microbiology and Microbial Infections, Volume 5 Medical Parasitology. Eds Cox, F.E.G., Kreier, J.P. and Wakelin, D. London: Hodder Arnold. pp: 361-410.

Hope, J., Wood, S.C., Birkett, C.R., Chong, A., Bruce, M.E., Cairns, D., Goldmann, W., Hunter, N. and 
Bostock, C.J. 1999. Molecular analysis of ovine prion protein identifies similarities between BSE and an experimental isolate of natural scrapie, CH1641. J. Gen. Virol. 80, 1-4.

Hörnlimann, B., Riesner, D. and Kretschmar, H. 2006. Prions in Humans and Animals. Berlin: De Gruyter.

Hull, D.L. 1980. Individuality and selection. Annu. Rev. Ecol. Evol. 11, 311-332.

Hunter, N. and Bossers, A. 2007. The PrP genotype as a marker for scrapie susceptibility. In: Prions in Humans and Animals, Eds. Hörnlimann, B., Riesner, D. and Kretschmar, H. Berlin: De Gruyter, pp: 640-647.

Hurley, P.J. 2003. A Concise Introduction to Logic 8th Ed. Belmont CA: Wadsworth/Thompson Learning.

Jablonka, E. and Lamb, M.J. 2005. Cambridge, Massachusetts: Evolution in Four Dimensions: Genetic, Epigenetic, and Symbolic Variation in the History of Life. MIT Press.

Jucker, M. and Walker, L.C. 2013. Self-propagation of pathogenic protein aggregates in neurodegenerative diseases. Nature 501, 45-51.

Kimberlin, R.H. and Walker, C.A. 1978. Evidence that the transmission of one source of scrapie agent to hamsters involves separation of agent strains from a mixture. J. Gen. Virol. 39, 487-496.

Kirschner, M. and Gerhart, J. 1998. Evolvability. Proc. Natl. Acad. Sci. U S A. 95, 8420-8427.

Konold, T., Davis, A., Bone, G., Bracegirdle, J., Everitt, S., Chaplin, M., Saunders, G.C., Cawthraw, S. and Simmons, M.M. 2007. Clinical findings in two cases of atypical scrapie in sheep: a case report. BMC Vet. Res. 3, 2.

Konold, T., Moore, S.J., Bellworthy, S.J. and Simmons, H.A. 2008. Evidence of scrapie transmission via milk. BMC Vet. Res. 4, 14.

Konold, T., Moore, S.J., Bellworthy, S.J., Terry, L.A., Thorne, L., Ramsay, A., Salguero, F.J., Simmons, M.M. and Simmons, H.A. 2013. Evidence of effective scrapie transmission via colostrum and milk in sheep. BMC Vet. Res. 9, 99.

Konold, T., Phelan, L.J., Clifford, D., Chaplin, M.J., Cawthraw, S., Stack, M.J. and Simmons, M.M. 2014. The pathological and molecular but not clinical phenotypes are maintained after second passage of experimental atypical bovine spongiform encephalopathy in cattle. BMC Vet. Res. 10, 243.

Lacroux, C., Corbiere, F., Tabouret, G., Lugan, S., Costes, P., Mathey, J., Delmas, J.M., Weisbecker, J.L., Foucras, G., Cassard, H., Elsen, J.M., Schelcher, F. and Andreoletti, O. 2007. Dynamics and genetics of PrPSc placental accumulation in sheep. J. Gen. Virol. 88, 1056-1061.

Lacroux, C., Simon, S., Benestad, S.L., Maillet, S., Mathey, J., Lugan, S., Corbiere, F., Cassard, H.,
Costes, P., Bergonier, D., Weisbecker, J.L., Moldal, T., Simmons, H., Lantier, F., Feraudet-Tarisse, C., Morel, N., Schelcher, F., Grassi, J. and Andreoletti, O. 2008. Prions in milk from ewes incubating natural scrapie. PLoS Pathog. 4(12), e1000238. doi: 10.1371/journal.ppat.1000238.

Laland, K.N., Uller, T., Feldman, M.W., Sterelny, K., Müller, G.B., Moczek, A., Jablonka, E. and OdlingSmee, J. 2015. The extended evolutionary synthesis: its structure, assumptions and predictions. Proc. R. Soc. B. 282, 20151019.

LeGrand, E.K. and Brown, C.C. 2002. Darwinian medicine: applications of evolutionary biology for veterinarians. Can. Vet. J. 43, 556-559.

Lewontin, R.C. 1970. The Units of Selection. Annu. Rev. Ecol. Evol. 1, 1-18.

Li, J., Browning, S., Mahal, S.P., Oelschlegel, A.M. and Weissmann, C. 2010. Darwinian evolution of prions in cell culture. Science 327, 869-872.

Ligios, C., Cancedda, G.M., Margalith, I., Santucciu, C., Madau, L., Maestrale, C., Basagni, M., Saba, M. and Heikenwalder, M. 2007. Intraepithelial and interstitial deposition of pathological prion protein in kidneys of scrapie-affected sheep. PLoS One 2(9), e859. doi: 10.1371/journal.pone.0000859.

Ligios, C., Cancedda, M.G., Carta, A., Santucciu, C., Maestrale, C., Demontis, F., Saba, M., Patta, C., DeMartini, J.C., Aguzzi, A. and Sigurdson, C.J. 2011. Sheep with scrapie and mastitis transmit infectious prions through the milk. J. Virol. 85, 1136-1139.

Lühken, G., Buschmann, A., Brandt, H., Eiden, M., Groschup, M.H. and Erhardt, G. 2007. Epidemiological and genetical differences between classical and atypical scrapie cases. Vet. Res. 38, 65-80.

Maddison, B.C., Baker, C.A., Rees, H.C., Terry, L.A., Thorne, L., Bellworthy, S.J., Whitelam, G.C. and Gough, K.C. 2009. Prions are secreted in milk from clinically normal scrapie-exposed sheep. J. Virol. 83, 8293-8296.

Maddison, B.C., Rees, H.C., Baker, C.A., Taema, M., Bellworthy, S.J., Thorne, L., Terry, L.A. and Gough, K.C. 2010. Prions are secreted into the oral cavity in sheep with preclinical scrapie. J. Infect. Dis. 201, 1672-1676.

Mahal, S.P., Browning, S., Li, J., Suponitsky-Kroyter, I. and Weissmann, C. 2010. Transfer of a prion strain to different hosts leads to emergence of strain variants. Proc. Natl. Acad. Sci. U S A 107, $22653-$ 22658.

Masujin, K., Shu, Y., Okada, H., Matsuura, Y., Iwamaru, Y., Imamura, M., Mohri, S. and Yokoyama, T. 2009. Isolation of two distinct prion strains from a scrapie-affected sheep. Arch. Virol. 154, 1929-1932. 
Maynard Smith, J. 1993. The Theory of Evolution. Cambridge: Cambridge University Press.

Mayr, E. 1997. The objects of selection. Proc. Natl. Acad. Sci. USA 94, 2091-2094.

Mayr, E. 2001. What Evolution Is. London: Orion Books.

Mayr, E. and Provine, W.B. (eds). 1980. Cambridge, Massachusetts: The Evolutionary Synthesis: Perspectives on the Unification of Biology. Harvard University Press.

Mazza, M., Iulini, B., Vaccari, G., Acutis, P.L., Martucci, F., Esposito, E., Peletto, S., Barocci, S., Chiappini, B., Corona, C., Barbieri, I., Caramelli, M., Agrimi, U., Casalone, C. and Nonno, R. 2010. Co-existence of classical scrapie and Nor98 in a sheep from an Italian outbreak. Res. Vet. Sci. 88, 478-485.

McIntyre, K.M., del Rio Vilas, V.J. and Gubbins, S. 2008. No temporal trends in the prevalence of atypical scrapie in British sheep, 2002-2006. BMC Vet. Res. 4, 13.

Millstein, R.L. 2017. Evolution. In: The Stanford Encyclopedia of Philosophy, Fall 2017 Edition, Ed. Zalta, E.N. https://plato.stanford.edu/entries/evolution/.

Moore, S.J., Smith, J.D., Greenlee, M.H., Nicholson, E.M., Richt, J.A., and Greenlee, J.J. 2016. Comparison of two US sheep scrapie isolates supports identification as separate strains. Vet. Pathol. 53, 1187-1196.

Morse, S.S. 1995. Factors in the emergence of infectious diseases. Emerg. Infect. Dis. 1, 7-15.

Moum, T., Olsaker, I., Hopp, P., Moldal, T., Valheim, M., Moum, T. and Benestad, S.L. 2005. Polymorphisms at codons 141 and 154 in the ovine prion protein gene are associated with scrapie Nor98 cases. J. Gen. Virol. 86, 231-235.

Nesse, R.M., Bergstrom, C.T., Ellison, P.T., Flier, J.S., Gluckman, P., Govindaraju, D.R., Niethammer, D., Omenn, G.S., Perlman, R.L., Schwartz, M.D., Thomas, M.G., Stearns, S.C. and Valle, D. 2010. Evolution in health and medicine Sackler colloquium: Making evolutionary biology a basic science for medicine. Proc. Natl. Acad. Sci. U S A. 107(Suppl. 1), 1800-1807.

Nesse, R.M. and Stearns, S.C. 2008. The great opportunity: evolutionary applications to medicine and public health. Evol. Appl. 1, 24-28.

Noble, D., Jablonka, E., Joyner, M.J., Müller, G.B. and Omholt, S.W. 2014. Evolution evolves: physiology returns to centre stage. J. Physiol. 11, 2237-2244.

OIE. 2017. Scrapie, Chapter 2.7.12. In Manual of Diagnostic Tests and Vaccines for Terrestrial Animals 2017. Paris: World Organisation for Animal Health.
Omenn, G.S. 2010. Evolution and public health. Proc. Natl. Acad. Sci. U S A. 107, 1702-1709.

Onodera, T., Ikeda, T., Muramatsu, Y. and Shinagawa, M. 1993. Isolation of scrapie agent from the placenta of sheep with natural scrapie in Japan. Microbiol. Immunol. 37, 311-316.

Orge, L., Oliveira, A., Machado, C., Lima, C., Ochoa, C., Silva, J., Carvalho, R., Tavares, P., Almeida, P., Ramos, M., Pinto, M.J. and Simas, J.P. 2010. Putative emergence of classical scrapie in a background of enzootic atypical scrapie. J. Gen. Virol. 91, 1646-1650.

Parry, H.B. 1966. Natural (spontaneous) scrapie in sheep. I. Clinical manifestation and general incidence, treatment, and related syndromes. In Report of Scrapie Seminar Held At Washington, D.C., January 27-30, 1964. Agricultural Research Service, US Department of Agriculture, pp: 95-103. https://archive.org/stream/report9153scra/report91 53scra_djvu.txt.

Parry, H.B. 1983. Scrapie Disease in Sheep: Historical, Epidemiological, Pathological and Practical Aspects of the Natural Disease. Ed. Oppenheimer, D.R. London: Academic Press.

Pattison, I.H. and Millson, G.C. 1961. Scrapie produced experimentally in goats with special reference to the clinical syndrome. J. Comp. Pathol. 71, 101-109.

Pattison, I.H., Hoare, M.N., Jebbett, J.N. and Watson. W.A. 1972. Spread of scrapie to sheep and goats by oral dosing with foetal membranes from scrapieaffected sheep. Vet. Rec. 90, 465-468.

Pattison, I.H., Hoare, M.N., Jebbett, J.N. and Watson, W.A. 1974. Further observations on the production of scrapie in sheep by oral dosing with foetal membranes from scrapie-affected sheep. Br. Vet. J. 130, 1xv-1xviii.

Perrott, M.R., Sigurdson, C.J., Mason, G.L. and Hoover, E.A. 2012. Evidence for distinct chronic wasting disease (CWD) strains in experimental CWD in ferrets. J. Gen. Virol. 93, 212-221.

Pigliucci, M. 2009. An extended synthesis for evolutionary biology. Ann. N.Y. Acad. Sci. 1168, 218-228.

Pigliucci, M. and Finkelman, L. 2014. The extended (evolutionary) synthesis debate: where science meets philosophy. BioScience 64, 511-566.

Prusiner, S.B. 2013. Biology and genetics of prions causing neurodegeneration. Ann. Rev. Genet. 47, 601-623.

Race, R., Jenny, A. and Sutton, D. 1998. Scrapie infectivity and proteinase K-resistant prion protein in sheep placenta, brain, spleen, and lymph node: implications for transmission and antemortem diagnosis. J. Infect. Dis. 178, 949-953. 
Rubenstein, R., Bulgin, M.S, Chang, B., SorensenMelson, S., Petersen, R.B. and Lafauci, G. 2012. PrPSc detection and infectivity in semen from scrapie-infected sheep. J. Gen Virol. 93,1375-1383.

Rubenstein, R., Chang, B., Gray, P., Piltch, M., Bulgin, M.S., Sorensen-Melson, S. and Miller, M.W. 2011. Prion disease detection, PMCA kinetics, and IgG in urine from sheep naturally/experimentally infected with scrapie and deer with preclinical/clinical chronic wasting disease. J. Virol. 85, 9031-9038.

Solforosi, L., Milani, M., Mancini, N., Clementi, M., Burioni, R. 2013. A closer look at prion strains: characterization and important implications. Prion 7, 99-108.

Soto, C. 2011. Prion hypothesis: the end of the controversy? Trends Biochem. Sci. 36, 151-158.

Terry, L.A., Howells, L., Bishop, K., Baker, C.A., Everest, S., Thorne, L., Maddison, B.C. and Gough, K.C. 2011. Detection of prions in the faeces of sheep naturally infected with classical scrapie. Vet. Res. 42, 65.

Thackray, A.M., Hopkins, L., Klein, M.A. and Bujdoso, R. 2007. Mouse-adapted ovine scrapie prion strains are characterized by different conformers of PrPSc. J. Virol. 81, 12119-12127.

Thackray, A.M., Hopkins, L., Lockey, R., Spiropoulos, J. and Bujdoso, R. 2011. Emergence of multiple prion strains from single isolates of ovine scrapie. J. Gen. Virol. 92, 1482-1491.

Thackray, A.M., Hopkins, L., Spiropoulos, J. and Bujdoso, R. 2008. Molecular and transmission characteristics of primary-passaged ovine scrapie isolates in conventional and ovine PrP transgenic mice. J. Virol. 82, 11197-11207.

Thackray, A.M., Lockey, R., Beck, K.E., Spiropoulos, J. and Bujdoso, R. 2012. Evidence for co-infection of ovine prion strains in classical scrapie isolates. $\mathrm{J}$. Comp. Pathol. 147, 316-329.

Tuo, W., O’Rourke, K.I., Zhuang. D., Cheevers, W.P., Spraker, T.R. and Knowles, D.P. 2002. Pregnancy status and fetal prion genetics determine PrPSc accumulation in placentomes of scrapie-infected sheep. Proc. Natl. Acad. Sci. U S A 99, 6310-6315.

Tuo, W., Zhuang, D., Knowles, D.P., Cheevers, W.P., Sy, M.S. and O'Rourke, K.I. 2001. Prp-c and Prp$\mathrm{Sc}$ at the fetal-maternal interface. J. Biol. Chem. 276, 18229-18234.

Ulvund, M.J. 2006. Clinical Findings in Scrapie. In Prions in Humans and Animals, Eds. Hörnlimann, B., Riesner, D. and Kretzschmar. Berlin: de Gruyter, pp: 398-407.

Ulvund, M.J. 2008. Ovine scrapie disease: do we have to live with it? Small Rumin. Res. 76, 131-140.

Uptain, S.M. and Lindquist, S. 2002. Prions as proteinbased genetic elements. Annu. Rev. Microbiol. 56, 703-741.

Van Keulen, L.J., Bossers, A. and van Zijderveld, F. 2008. TSE pathogenesis in cattle and sheep. Vet. Res. 39, 24.

Vascellari, M., Nonno, R., Mutinelli, F., Bigolaro, M., Di Bari, M.A., Melchiotti, E., Marcon, S., D’Agostino, C., Vaccari, G., Conte, M., De Grossi, L., Rosone, F., Giordani, F. and Agrimi, U., 2007. PrPSc in salivary glands of scrapie-affected sheep. J. Virol. 81, 4872-4876.

Vulin, J., Beck, K.E., Bencsik, A., Lakhdar, L., Spiropoulos, J. and Baron, T. 2012. Selection of distinct strain phenotypes in mice infected by ovine natural scrapie isolates similar to $\mathrm{CH} 1641$ experimental scrapie. J. Neuropathol. Exp. Neurol. 71, 140-147.

Waller, P.J. 1997. Anthelmintic resistance. Vet. Parasitol. 72, 391-405.

Watts, J.C., Giles, K., Patel, S., Oehler, A., DeArmond, S.J. and Prusiner, S.B. 2014. Evidence that bank vole PrP is a universal acceptor for prions. PLoS Pathog. 10, e1003990.

Weller, R.O., Djuanda, E., Yow, H-Y. and Carare, R.O. 2009. Lymphatic drainage of the brain and the pathophysiology of neurological disease. Acta. Neuropathol. 117, 1-14.

Wemheuer, W.M., Benestad, S.L., Wrede, A., Wemheuer, W.E., Brenig, B., Bratberg, B. and Schulz-Schaeffer, W.J. 2011. PrPSc spreading patterns in the brain of sheep linked to different prion types. Vet. Res. 42, 32.

Wenborn, A., Terry, C., Gros, N., Joiner, S., D’Castro, L., Panico, S., Sells, J., Cronier, S., Linehan, J.M., Brandner, S. and Saibil, H.R. 2015. A novel and rapid method for obtaining high titre intact prion strains from mammalian brain. Sci. Rep. 5, 10062.

Wickner, R.B., Edskes, H.K., Roberts, B.T., Baxa, U., Pierce, M.M., Ross, E.D. and Brachmann, A. 2004. Prions: proteins as genes and infectious entities. Genes Dev. 18, 470-485.

Williams, E.S. 2005. Chronic wasting disease. Vet. Pathol. 42, 530-549.

Wilson, D.R., Anderson, R.D. and Smith, W. 1950. Studies in scrapie. J. Comp. Pathol. 60, 267-282.

Yokoyama, T., Masujin, K., Schmerr, M.J., Shu, Y., Okada, H., Iwamaru, Y., Imamura, M., Matsuura, Y., Murayama, Y. and Mohri, S. 2010. Intraspecies prion transmission results in selection of sheep scrapie strains. PLoS One 5, e15450. 